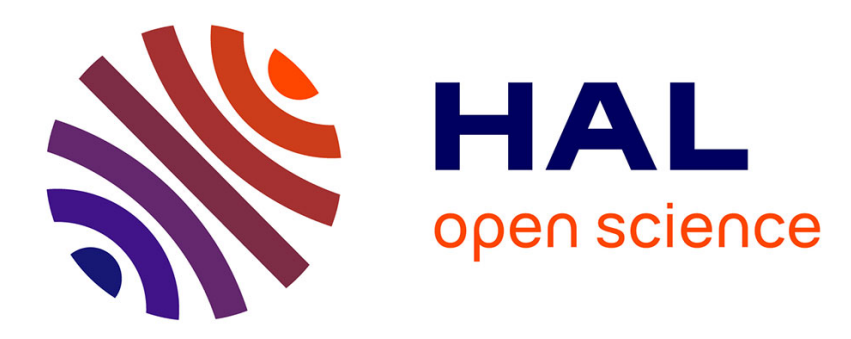

\title{
Las adaptaciones de las vidas de santo en la poesía de José Pérez de Montoro
}

Alain Begue

\section{To cite this version:}

Alain Begue. Las adaptaciones de las vidas de santo en la poesía de José Pérez de Montoro. Homenaje a Henri Guerreiro. La hagiografía entre historia y literatura en la España de la Edad Media y del Siglo de Oro, 2005. hal-02522939

\section{HAL Id: hal-02522939 \\ https://hal.science/hal-02522939}

Submitted on 14 Apr 2020

HAL is a multi-disciplinary open access archive for the deposit and dissemination of scientific research documents, whether they are published or not. The documents may come from teaching and research institutions in France or abroad, or from public or private research centers.
L'archive ouverte pluridisciplinaire HAL, est destinée au dépôt et à la diffusion de documents scientifiques de niveau recherche, publiés ou non, émanant des établissements d'enseignement et de recherche français ou étrangers, des laboratoires publics ou privés. 


\title{
Las adaptaciones de las vidas de santo en la poesía de José Pérez de Montoro
}

\author{
Alain Bègue \\ LEMSO, Université de Toulouse-Le Mirail/EHEH, Casa de Velázquez
}

\begin{abstract}
Siguen siendo muy pocos los estudios dedicados a la poesía religiosa del siglo XVII y casi inexistentes en lo que respecta a la hagiográfica. No obstante, este hecho no refleja en absoluto la destacada importancia numérica que alcanzaron las composiciones poéticas que celebran la virtuosa, gloriosa, milagrosa y, por lo tanto, ejemplar vida de los santos. A semejanza de no pocos autores contemporáneos suyos, el poeta José Pérez de Montoro (1627-1694), cuya producción poética se desarrolló, como lo señalé en un trabajo anterior, en gran parte durante las décadas 1680 y 1690, compuso obras poéticas con motivo de la celebración de diversos santos. La notoriedad que adquirió en Cádiz como poeta así como los estrechos vínculos que le unieron a las distintas instituciones religiosas de la ciudad portuaria — fue miembro de la congregación del Santísimo Sacramento, sita en el convento gaditano de los Agustinos; tuvo familiares tanto en el clero regular (una sobrina política en el convento de las monjas clarisas de la Candelaria, barrio en el que nuestro poeta vivía junto con su esposa, doña Catalina Calderón de la Barca) como en el secular (un tío y un hermano de doña Catalina, racioneros del cabildo catedralicio) y fue el villanciquero "oficial” de la catedral gaditana entre 1687 y 1694 explican la presencia de veintitrés composiciones hagiográficas en sus Obras pósthumas ${ }^{1}$, publicadas en el año de 1736. Estas obras, que forman nuestro corpus textual y que pertenecen — según la tipología establecida por Bruce W. Wardropper — a la poesía circunstancial y ocasional, fueron mayoritariamente poemas encargados por instituciones religiosas (conventuales o seculares) o civiles. Así, pues, ciertos poemas fueron escritos con motivo de la festividad de santos fundadores de órdenes instaladas en Cádiz (san Agustín, san Francisco de Asís, santa Clara de Asís, san Felipe Neri), de patronos de instituciones de beneficencia (santa María Magdalena, patrona de la casa de los niños expósitos de Cádiz), o también para celebrar la canonización de algún santo (san Juan de Sahagún en 1691). Del mismo modo, Pérez de Montoro prestó en alguna ocasión su pluma a instituciones civiles, como ocurrió para una fiesta que organizó el gremio de mercaderes en nombre de san Francisco. Completan el panorama de nuestros poemas ocasionales los poemas escritos por nuestro autor durante un certamen poético dedicado a san Alberto Magno así como los dedicados a santos que gozaban de una especial devoción en España (san Antonio de Padua, san Nicolás de Bari, san Nicolás de Tolentino y santo Tomás de Villanueva) y a santos neotestamentarios (san José y san Pedro).
\end{abstract}

\section{Hacia un estudio estructural del poema hagiográfico: el ejemplo de Pérez de Montoro}

Como etapa previa al estudio de la obra hagiográfica de Pérez de Montoro y con el motivo de insertarla en el marco genérico en el que evolucionaba, procedimos a una lectura sistemática y pormenorizada de las obras de autores coetáneos de nuestro poeta (Sor Juana Inés de la Cruz (ca. 1651-1695), Manuel de León Marchante (1631-1680), Juan de Ovando Santaren (1624-1706), Bernardino de Rebolledo (1597-1676), Vicente Sánchez, Antonio de Solís (1610-1686), José Tafalla y Negrete). Dicha lectura nos permitió destacar algunas constantes en los poemas de santos del siglo XVII, constantes que procuraremos señalar a lo largo de nuestro estudio.

En primer lugar, pudimos comprobar un uso preferente de ciertas formas o géneros métricos para la elaboración de los poemas hagiográficos. Se trata, por orden decreciente de importancia, del romance, al que hemos sumado su vertiente jocosa, la jácara, seguidos por el villancico, en el que integramos la forma que algunos estudiosos han llamado letrillas, y las quintillas. Dado el conocimiento que tenía Pérez de Montoro del género villanciqueril, no ha de sorprendernos, pues, la fuerte predominancia de éste entre las formas recurridas por nuestro autor a la hora de componer sus obras. En efecto, podemos comprobar la presencia en su corpus hagiográfico de doce villancicos (50\%), a los que se suman cinco jácaras (25\%), tres quintillas $(12,5 \%)$, una canción alirada (4,16\%), un sexteto lira (4,16\%) y unas sextillas (4,16\%). Tampoco debe extrañarnos el uso del romance, de la jácara y de las quintillas, puesto que, además de caracterizar al género, estas formas métricas suelen constituir las coplas de los villancicos hagiográficos. De ahí que entre los doce villancicos, cinco tienen como coplas unas quintillas, cuatro un romance y tres una jácara.

Del mismo modo, destacamos ciertos rasgos estructurales internos comunes a las obras de santos. En la primera estrofa o, en el caso de los villancicos, en la cabeza, el autor suele anunciar la forma métrica empleada, presentar el objeto y la finalidad de la obra, y/o captar la benevolencia y la atención del auditorio. Cabe señalar que tenemos aquí una evidente contaminación del género villanciqueril como lo comprueban

\footnotetext{
${ }^{1}$ En adelante $O P$.

2 Bruce W. Wardropper (1985), pp. 196-198 (pp. 195-210).
} 
ciertos procedimientos destinados a captar la atención del público, procedimientos fundados principalmente en el uso de la modalidad discursiva yusiva y la creación de interés en el auditor:

$$
\begin{aligned}
& \text { Aunque en su poco primor } \\
& \text { den mis quintillas enfado, } \\
& \text { la historia más superior } \\
& \text { oigan de un pobre llagado } \\
& \text { por las llagas del Señor. } \\
& (O P, \text { II, p. } 60 \text {, vv. } 1-5)
\end{aligned}
$$

\author{
Oigan prodigios de un santo \\ cuyos triunfos, cuyas glorias, \\ hasta los pobres las cantan \\ cuando sus miserias lloran. \\ $(O P$, II, p. 100, vv. 1-4)
}

Después de la estrofa inicial —o después de la cabeza, en el caso de los villancicos—, se suceden las distintas estrofas constitutivas de las coplas — cuartetas para los romances y las jácaras, pues, como señaló Antonio Alatorre, el romance octosílabo ya se organizaba desde fines del XVI en una sucesión de cuartetas con autonomía semántica ${ }^{3}$, o quintillas_ que van narrando la vida y los milagros del santo concernido. Por lo general, cada una de ellas tiene una doble función informativa y conceptista que acaba imponiendo su estructuración binaria. En efecto, la estrofa se inicia con un primer movimiento informativo, que se apoya generalmente en el elemento hagiográfico, y remata en un concepto o una agudeza verbal, desarrollados en los dos últimos versos de la estrofa, como lo comprobaremos más adelante. Además, cabe señalar que los temas hagiográficos escogidos por nuestro autor nunca se repiten en la misma obra. Y es que, a diferencia de las vidas de santos que pudieron compilar Pedro de Ribadeneira o Alonso de Villegas en sus Flores sanctorum y que tendían a la amplificatio, las composiciones hagiográficas de nuestro autor tuvieron que ceñirse a ciertas formas poéticas que, si bien eran apropiadas para la narración por su extensión, no dejaban de tener un límite en su extensión. Así, pues, nuestro autor tuvo que proceder a una selección de los datos más definitorios de los santos tratados y/o a una reducción del material hagiográfico en un ejercicio de síntesis. Lo comprobamos en la utilización de figuras retóricas de acumulación — generalmente la enumeración- y de paralelismo, tal como sucede claramente en el poema siguiente, dedicado a san Nicolás de Bari:

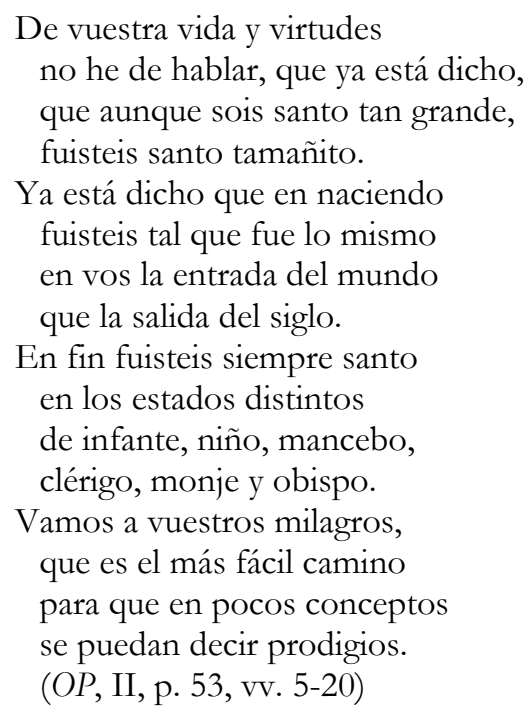

Pérez de Montoro, tras anunciar su voluntad de no relatar la vida del santo, procede a una síntesis de la misma que insiste en su humildad (v. 8), su religiosidad precoz (v. 10-12) y ejemplar en todos los estados de su vida (v. 14-16). Se trata aquí, desde luego, de un caso extremo en el que el autor afirma su clara voluntad de dedicarse casi exclusivamente a narrar los milagros del santo, pero se podría aducir más ejemplos de este procedimiento sintetizador. Del mismo modo, la limitación textual a la que queda sometido Pérez de Montoro se traduce en muchas ocasiones en una escritura alusiva en la que el autor no hace sino evocar un dato hagiográfico sin desarrollarlo. Veamos la evocación que hace de uno de los milagros atribuidos a san Nicolás de Bari:

También se cuenta de vos, pero esto diré quedito, porque no oigan las doncellas,

\footnotetext{
${ }^{3}$ Antonio Alatorre (1977), pp. 345-349.
} 
que dais dotes, y maridos.

(OP, II, p. 54, vv. 45-48)

Se trata, como bien se sabe, del episodio del rescate, por parte del santo, de la virtud y castidad de tres hijas destinadas a la prostitución por su padre, situación a la que quedaban abocadas debido a su gran pobreza. El santo, afligido por el hecho, había ofrecido su ayuda de forma anónima al arrojar por su ventana tres bolsas llenas de monedas de oro para que las mujeres pudieran constituir su dote y, de esta forma, contraer matrimonio. En este ejemplo, síntesis y alusión se completan para ir formando uno de los capítulos hagiográficos.

Por otra parte, un análisis de la organización de la materia hagiográfica, que a nuestro parecer tanto debe al Flos sanctorum de Ribadeneira como a la iconografía del momento, nos permitió destacar dos tipos de narración distintos en la obra poética de nuestro autor setabense: una cronológica o, mejor dicho, pseudocronológica, y otra temática.

\section{Narración cronológica}

El procedimiento más socorrido de Pérez de Montoro — que aparece en 13 de los 23 poemas hagiográficos $(56,5 \%$ - reside en la narración lineal y pseudo-cronológica de la vida del santo. Los elementos hagiográficos seleccionados por el autor se suceden así generalmente desde el nacimiento del santo hasta su muerte o hasta sus milagros post-mortem. Decimos generalmente porque, como podemos comprobar, a modo de ejemplo, en las quintillas dedicadas a san Nicolás de Tolentino (Cf. Ejemplo 1), los principales elementos hagiográficos escogidos de los Flores sanctorum observan un desarrollo lineal y cronológico, pero, otros muchos son adelantados o retrasados por nuestro autor. Así, por ejemplo, los versos 16-20, que realzan el precoz y alto grado de penitencia del santo mediante sus ayunos, aluden a hechos narrados en el Flos sanctorum de Pedro de Ribadeneira ${ }^{4}$ después de la profesión del santo como monje agustino, recogidos en cambio por Pérez de Montoro en los versos 26-30. Cabe precisar, no obstante, que nuestro autor no olvida casi ningún elemento de la vida del santo italiano, omitiendo únicamente sus flagelaciones con una cadena de hierro ${ }^{5}$.

A este tipo de obras pertenecen los dos villancicos compuestos con motivo de la canonización de san Juan de Sahagún en 1691 y que, debido a la importancia y solemnidad del contexto, fueron objeto de una mayor elaboración formal. Se trata en efecto de dos composiciones escritas polifónicas, de las cuales una tiene una estructura tripartita (introducción, estribillo y coplas), aspecto formal que, como señalamos en nuestra tesis doctoral, implica cierta complejidad en su interpretación e indica que fue probablemente interpretada en la catedral de Cádiz.

\section{Narración selectiva y temática}

Junto con la narración de forma pseudo-cronológica, nuestro autor hace un segundo uso de la materia hagiográfica que radica en la selección de datos para una elaboración temática de sus poemas. Estos poemas pueden ser pluritemáticos o monotemáticos.

En seis ocasiones (26,1\%), Pérez de Montoro escribió poemas en los que desarrolla de forma limitada la vida de un santo, bien dedicándose únicamente a la relación de sus milagros, como en el caso de san Nicolás de Bari como vimos antes, bien a través de un prisma específico, como sucede en los poemas de ejemplificación (a través de las virtudes de san Francisco de Asís) o de encargo (san Francisco de Asís y santa María Magdalena como santos tutelares).

En éstos, al dirigirse, pues, a un auditorio específico, el escritor valenciano procedió en los poemas dedicados a san Francisco de Asís, patrón que fue del gremio de mercaderes, y santa María Magdalena, tutora de la casa de niños expósitos de la ciudad de Cádiz, a una selección de los elementos hagiográficos que mejor se adaptaban a la naturaleza de ambas instituciones. Veamos, a modo de ejemplo, las quintillas compuestas para la fiesta de san Francisco de Asís. Tienen su originalidad en una elaboración «en metáfora de» tal como hiciera Alonso de Ledesma en sus Conceptos espirituales y morales, publicados entre 1606 y 1612. Pérez de Montoro parte del elemento hagiográfico más acorde con la naturaleza de su comanditario, en este caso el oficio paterno del santo, mercader, para ir narrando su vida a través del inevitablemente reductor prisma mercantil $(C f$. Ejemplo 2).

En cambio, Pérez de Montoro sólo escribió una composición elaborada a partir de un repaso de la vida de un santo dentro de una perspectiva claramente ejemplificadora. Se trata de un villancico dedicado a san Francisco de Asís y estructurado en forma de regla monástica. La humildad (primera y séptima estrofas), la

\footnotetext{
4 En adelante Ribadeneira.

${ }^{5}$ Ribadeneira, p. 508b-509a.
} 
pobreza (segunda), la mortificación (tercera, octava y novena), la sumisión (cuarta), el silencio (quinta) y la meditación (sexta) del santo están presentados como ejemplos a seguir por el auditorio tal como acaba pidiéndolo el poeta en las cuartetas finales de la obra (Cf. Ejemplo 3).

Otro caso particular y de gran originalidad es el villancico dedicado a los santos Francisco de Asís y Domingo de Guzmán (Cf. Ejemplo 4). Son muy pocas en la poesía religiosa del siglo XVII las obras con doble advocación y en dicha obra Pérez de Montoro recurre a elementos hagiográficos que le permiten establecer conexiones paralelísticas y/o antitéticas entre los dos santos, conexiones que, en cinco de las once quintillas, quedan localizadas en los dos últimos versos de las estrofas, tal como vemos en la siguiente estrofa donde el autor muestra que la recompensa divina a los esfuerzos de los dos santos se tradujeron en los conocimientos de los misterios divinos por parte de santo Domingo y los estigmas en el caso de san Francisco:

Las cinco señas benditas

que son purpúreas empresas

de piedades infinitas,

si Domingo manuescritas,

las tuvo Francisco impresas.

(OP, II, p. 59, vv. 35-39)

Por otro lado, las obras monotemáticas del corpus textual de Pérez de Montoro — cuatro en total $(17,4 \%$ - recogen uno, en la mayoría de los casos, o varios elementos hagiográficos, que permitirá al autor desarrollar un único y mismo tema. Son los tres poemas escritos con motivo de un certamen poético y dedicados a san Alberto Magno, y el poema escrito en honor a san Antonio de Padua fundado en la histórica querella que opone a Castilla y Portugal acerca de su patronato.

De la vida de san Alberto Magno — santo beatificado en 1622 y no canonizado hasta 1931—, nuestro poeta setabense se limitó a destacar sus grandes conocimientos teológicos — «ol de ciencia» que llegaron a caracterizarlo en la iconografía cristiana pues en una de sus dos representaciones aparece cubierto con un bonete de doctor y teniendo un libro en sus rodillas ${ }^{6}$. El carácter monotemático de estas obras se debe a su contexto académico, esto es, a su supeditación a los temas proporcionados por las autoridades del certamen como lo atestigua uno de los títulos: «Asunto que en una academia se dio en Cádiz a Montoro, de un hereje que fue a argüir con san Alberto y el santo le convirtió». Constatamos asimismo una supresión de los procedimientos iniciales de captatio, supresión que se debe seguramente a la desaparición del contexto celebrativo y festivo en el que suele insertarse el género villanciqueril, así como la utilización excepcional de estrofas y metros italianizantes (canción alirada y sexteto lira) y de sextillas.

A esta altura de nuestra ponencia, podemos hacer ya algunas observaciones. Cabe notar la ausencia, en la obra de Pérez de Montoro, de obras hagiográficas de carácter lírico que, aunque siguen siendo (poco) utilizados por autores como León Marchante, no deja de reflejar una situación general en la poesía de finales del siglo XVII. Destacamos asimismo que dichas obras no tienen como propósito sino insertarse en un movimiento y permitir la adhesión de su autor a una comunidad ya bien definida, fuera de luchas teológicas o políticas. Son, pues, composiciones poéticas de carácter social y celebrativo que, como vamos a ver ahora, se aproximan a otras obras de carácter público. Por otra parte, nos es forzoso subrayar un rasgo omnipresente en el corpus textual de nuestro autor que radica en una aparente falta de decoro debida a la invasión de cierto prosaísmo y de lo cotidiano. Ahora bien, a nuestro parecer este rasgo, compartido por los escritores de la segunda mitad del Setecientos, tiene que ver con el carácter público de la interpretación de los poemas.

\section{La materia hagiográfica supeditada a la retórica poética desarrollada en tiempos de los novatores.}

En efecto, a la par que los villancicos litúrgicos, los poemas hagiográficos tenían que ser interpretados ante un auditorio y, como debió de suceder para sus coetáneos, Pérez de Montoro vio seguramente en ellos una oportunidad más de lucirse y de hacer alarde de sus dotes, tal como lo hacía en las no pocas academias, certámenes y justas poéticas en las que participó, como lo atestiguan numerosos títulos de sus poemas. Ahora bien, la poesía de la segunda mitad del siglo XVII conoce, como lo subrayó ya el profesor Jeremy Robbins, una fuerte influencia de las academias literarias y una evolución marcada entre otras cosas por la desaparición de la

\footnotetext{
${ }^{6}$ Louis Réau (1958).
} 
retórica de la presencia del Yo poético ${ }^{7}$ y por el desarrollo, como lo señaló acertadamente Jesús Pérez Magallón, de una retórica de la sociabilidad y conversabilidad ${ }^{8}$, que se traduce por el uso preferente de determinados conceptos y agudezas verbales. Pérez Magallón indicó a este respecto que «el núcleo de la Agudera y arte de ingenio de Gracián establece tipos de conceptos que parecen hechos a medida de la poesía académica»", añadiendo que los conceptos y agudezas verbales de «la mayoría de la poesía académica cuadra a la perfección en lo que Gracián define como "agudeza incompleja” (t. I, p. 62), "libre” o "suelta”»", esto es, la sucesión de un número indefinido de conceptos.

Ahora bien, ya señalamos antes cómo los poemas hagiográficos de Pérez de Montoro se organizaban estructuralmente en una sucesión de estrofas que culminan cada una en un concepto y/o una agudeza verbal. Pues, estos conceptos y agudezas se ciñen a una determinada tipología en la que predominan las figuras paralelísticas. En la citada obra dedicada a san Nicolás de Tolentino aparecen en ocho de las dieciséis quintillas. La primera quintilla se funda en un quiasmo («ya que todo el santo día / tengo por día de santo», vv. 4-5), la cuarta en un paralelismo imperfecto sinonímico («él mismo se destetaba, / pero él mismo no comía.», vv. 1920), la quinta en un paralelismo imperfecto («daba mayor esperanza / de su mayor caridad.», vv. 24-25), la séptima y la octava en un paralelismo imperfecto antitético («que para él todo era orden, / y para ella confusión.», vv. 34-35, y «no fue el santo muy su amigo, / fue siempre muy paniaguado.», vv. 39-40), la decimotercera en un paralelismo imperfecto final y antitético («pues hasta después de muerto, / hizo milagros en vida.», vv. 64-65), la decimocuarta en un paralelismo imperfecto («panecillos reservados / y milagros amasados.», vv. 69-70), la decimosexta en un paralelismo imperfecto final («los que no son sus parientes, / ¿qué no harán sus hermanos?», vv. 79-80). Entre los procedimientos harto utilizados por nuestro autor figuran también la relexicalizacón de refranes e idiotismos — tal como ocurre en la segunda quintilla en la que nuestro poeta alude a la petición de intercesión hecha a san Nicolás de Bari por parte de los padres de Nicolás de Tolentino mediante una reconstrucción del refrán «El consejo no es bien recibido donde no es pedido», recogido por Gonzalo Correas en su Vocabulario de refranes ${ }^{11}$ («Si el hijo es como el consejo, / el mejor será el pedido.», vv. 9-10)—, la creación de asociaciones mediante el recurso a sustantivos pertenecientes a un mismo grupo léxico — como en la sexta quintilla donde el sol, símbolo atribuido a san Agustín de Hipona, está asociado a la estrella otorgado por Dios a san Nicolás de Tolentino-, o la dilogía, como en la undécima estrofa donde el verbo «cojear» significa a un mismo tiempo el acto físico de cojear y la falta de fuerza mental («y con quebrarle una pierna, / nunca le vio cojear»).

Estos procedimientos, que son los más recurrentes en la obra de Pérez de Montoro, resultan ser asimismo los más socorridos en la poesía de finales del siglo XVII y principios del siglo XVIII. Abundan en la obra de Vicente Sánchez, León Marchante, Tafalla y Negrete u Ovando Santaren, y eso cualquiera que sea el tema abordado y hasta tal punto que, a veces, parecen forzar la materia tratada. Y en lo que respecta la materia hagiográfica, no se convierte sino en un soporte para el desarrollo de lo que parece ser una nueva retórica poética en tiempos de los novatores.

Con el presente estudio hemos tenido el doble propósito de presentar las características estructurales y temáticas propias de las obras hagiográficas del poeta de Játiva José Pérez de Montoro insertándolas en su contexto genérico y sincrónico. Esta presentación nos permitió destacar en la obra de nuestro autor ciertos rasgos retóricos compartidos por sus contemporáneos en un período desdeñado hasta la fecha por la crítica literaria por la profunda crisis que sufrió y por su prosaísmo, un período que no deja de presentar sin embargo signos de cambio estético y de renovación poética, consciente o inconsciente, que se prolongarán hasta bien entrado el siglo XVIII y que participaron en la evolución de la poesía española hacia el Neoclasicismo.

\footnotetext{
${ }^{7}$ Jeremy Robbins (1997), p. 1: «Their importance lies not only in the central role they played in the lives of seventeenth-century writers, but also in the profound effect they had on the direction taken by poetry over the course of the century».

8 Jesús Pérez Magallón (2001), p. 457.

9 Jesús Pérez Magallón (2001), p. 459.

10 Jesús Pérez Magallón (2001), p. 459.

11 Gonzalo Correas, Vocabulario de refranes y frases proverbiales, 1. 380.
} 


\section{DOCUMENTOS ANEXOS}

\section{Ejemplo 1: NARRACIÓN PSEUDO-CRONOLÓGICA}

A san Nicolás de Tolentino.

Quintillas.

La vida y milagros canto

de Nicolás a porfía, que quiero alargarme tanto, ya que todo el santo día tengo por día del santo.

Su padre andaba afligido sin sucesión (que era viejo) y dijo entre sí advertido: «Si el hijo es como el consejo, el mejor será el pedido.»

Conque hoy de su quebranto, de otro Nicolás vio fijo su gozo, con tal espanto que conociendo a su hijo, le tuvo por otro santo.

Nació el niño, y ya sabía lo que el ayuno importaba, con que cada tercer día, él mismo se destetaba pero él mismo no comía.

De su heroica santidad se tuvo gran confianza, pues cada día en su edad, daba mayor esperanza de su mayor caridad.

Trató de elegir camino donde no fuese su huella la de errante peregrino, y diole Dios una estrella, con luz del Sol de Augustino.

Aquí, pues, la religión vio en el compuesto desorden de su mortificación que para el todo era orden, y para ella confusión.

De su abstinencia informado fue el refectorio testigo, pues aunque en lo frecuentado no fue el santo muy su amigo, fue siempre muy paniaguado.

Su vigilia admiración causó, porque se acostaba tarde, o nunca, en conclusión, siendo así que siempre estaba recogido a la oración.

Con duro cilicio andaba, y aunque a la sangrienta mina de sus carnes se inclinaba, siempre fue la disciplina con lo que más se pegaba. 
quiso el demonio apurar, y con quebrarle una pierna nunca le vio cojear.

La obediencia le mandó que una perdiz se comiera, con que jamás consiguó comer cosa tan ligera pues desde el plato voló.

De su piedad conocida, raros prodigios por cierto vio quien su nombre apellida, pues hasta después de muerto, hizo milagros en vida.

Para los necesitados que le buscan afligidos tiene siempre reservados panecillos prevenidos, y milagros amasados.

Todo lo quiere aliviar, y por llevarse las palmas de pedir, y de ayudar, trabaja porque las almas se vayan a descansar. (OP, II, p. 92-94)

\section{NARRACIÓN LIMITADA}

\section{Ejemplo 2: «En metáfora de»}

Letra a la fiesta que el gremio de mercaderes hizo a nuestro glorioso Padre san Francisco de Asís. Quintillas.

Aunque en su poco primor den mis quintillas enfado, la historia más superior oigan de un pobre llagado por las llagas del Señor;

que aunque esta festividad hoy en su aplauso se emplea, si he de hablar con claridad, la fiesta le hace que sea pobre de solemnidad.

Mercader fue, y en rigor, yo no entiendo su recato, pues siguió a Dios su fervor, y logró tener amor, apartándose del trato.

Los pobres que le buscaban para cualquiera aflicción, ya en la tienda no le hallaban, $\mathrm{y}$ al santo se le rasgaban las telas del corazón.

El mundo en orden metió, y cuando a infinitos rotos hábito nuevo les dio, dicen que no se enojó, pero les echó sus votos.

Pobre fue, y es de advertir que dio a sus hijos sin cuenta 
de comer, y de vestir,

y no obstante dejó renta,

cuanto se pueda pedir.

Pero esto engaño a ser viene,

o no sé cómo lo entienda,

puesto que, aunque más se abstiene,

sólo su cuerpo es la bacienda

que en su religión se tiene.

No tuvo jamás dineros,

pues aunque le daban hartos,

dejó entre sus compañeros,

muchos sacos de dineros,

pero ninguno de cuartos.

El diablo, que siempre vela, quiso hacerle una vez tiro, y él, por huir su cautela, iba buscando el Retiro,

y fue a dar en la Zarzuela.

En su corazón estaba siempre Dios para premiar la fe con que le adoraba, $y$ al santo no le pesaba, pues nunca le quiso alzar.

Muchos prodigios obró, pues con piedad conocida, tantos enfermos sanó, que, aún después que se murió, hizo milagros en vida.

$\mathrm{Y}$ así es justo que a su honor dediquen, sin más contiendas, fiesta de tanto primor, que no le hallarán mejor, aunque anden todas las tiendas. (OP, II, p. 60-61)

Ejemplo 3: Ejemplaridad del santo

Coplas.

Manda que el abatimiento se profese, viendo que hoy su humildad goza la silla que la soberbia perdió.

Manda que de las riquezas se haga desestimación, pues sólo puede el desprecio hacer volar su valor.

Manda que porque se inclinen a la mortificación, vean lo bueno que está, con la vida que él se dio.

Manda que se reconozca en todo fiel corazón las señales de que es siervo por las llagas del Señor.

Manda que sea el silencio costumbre que inclinación sólo fue en él, porque fue lo que más se le pegó.

Manda que todos mediten, 
porque la santa oración

es un tan bello ejercicio, que es para alabar a Dios.

Manda sus hijos se hagan pequeños a oposición, viendo que él se hizo tan grande a puro hacerse menor.

Mándales también que al áspid, al basilisco, y dragón, calzados le pisen bien, pero descalzos mejor.

Manda que a la Providencia encarguen su refacción, porque el ayuno, y el plato tengan un mismo sabor.

Manda a su orden tercera que haga, pues se levantó con las preeminencias de orden, méritos de religión.

Pues si por ser tan ardiente serafín su fundador, no puede la competencia, practique la imitación.

Esto se manda en presencia del Monarca superior, Dios en Pan, Dios en Palabra, a quien alaba mi voz. (OP, II, p. 55-56, v. 9-56)

\section{Ejemplo 4: Poema dedicado a dos santos}

Venga la piedad y el celo a este sagrado jardín de virtudes, cuyo anhelo produjo en Domingo un Cielo y en Francisco un Serafín.

En Cristo fueron hermanos, pues porque se socorriera la Religión, a dos manos proveyó el Señor su era de dos tan fecundos granos.

De Patriarca el honor le dio Inocencio tercero a Domingo; y en rigor, Francisco nació primero, pero quiso ser menor.

Las cinco señas benditas que son purpúreas empresas de piedades infinitas, si Domingo manuescritas, las tuvo Francisco impresas.

En Domingo era atrición celebrar el Sacramento, y en su humilde confusión llegó Francisco al memento, mas no a la consagración.

Para el de Dios verdadero templo, en que es para la cruz, y sacrificio el cordero, 
si Domingo fue luz, Francisco fue candelero.

Ambos siguiendo el divino

celestial impulso que

la caridad les previno, anduvieron siempre a pie, cada cual por su camino.

Ambos sus milagros ciertos

hacen siempre, y tal vez juntos, pues ya en Cortes, ya en desiertos, si uno da vida a difuntos, otro resucita muertos.

Ambos, según la licencia que consiguieron en Roma, dejaron por providencia ya que no con que se coma, con que se haga penitencia. (OP, II, p. 58-60, v. 20-64) 


\section{BIBLIOGRAFÍA CITADA}

ALATORRE, Antonio, «Avatares barrocos del romance (de Góngora a Sor Juana Inés de la Cruz)», Nueva Revista de Filología Hispánica, México, 26/2 (1977), p. 341-459.

CORREAS, Gonzalo, Vocabulario de refranes y frases proverbiales (1627), edición de Louis Combet, revisada por Robert Jammes y Maïté Mir-Andeu, Madrid, Castalia, 2000 (Nueva Biblioteca de Erudición y Crítica, 19).

GONZÁLEZ CAÑAL, Rafael, (ed.), Edición crítica de los Ocios del Conde de Rebolledo, Cuenca, Servicio de Publicaciones de la Universidad de Castilla-La Mancha, 1997 (Ediciones críticas, 3).

GRACIÁN, Baltasar, Agudeza y arte de ingenio, ed. de Evaristo Correa Calderón, Madrid, Castalia, 1987 (Clásicos Castalia, 14 y 15). 2 tomos.

JUANA INÉS DE LA CRUZ, Sor, Obras completas, ed. de Alfonso Méndez Plancarte, México-Buenos Aires, Fondo de Cultura Económica, 1951-1955 (Biblioteca Americana. Serie de literatura colonial ). 4 tomos.

LEDESMA, Alonso de, Conceptos espirituales y morales, ed., intr. y notas de Eduardo Juliá Martínez, Madrid, CSIC, Instituto «Miguel de Cervantes», 1969 (Biblioteca de Antiguos Libros Hispánicos. Serie A, XXVII-XXIX). 3 tomos.

LEÓN MARCHANTE, Manuel de, Obras poeticas posthumas, Madrid, Gabriel del Barrio, 1722 (Tomo 1), 1733 (Tomo 2).

OVANDO SANTARÉN, Juan de, Ocios de Castalia en diversos poemas, Málaga, Mateo López Hidalgo, 1663.

PÉREZ-MAGALLÓN, Jesús, «Hacia un nuevo discurso poético en el tiempo de los novatores», Bulletin Hispanique, 2 (2001), pp. 449-479.

PÉREZ DE MONTORO, José, Obras posthumas lyricas, Madrid, Antonio Marín, 1736. Tomo 2.

RIBADENEIRA, Pedro de, Flos sanctorum o libro de las vidas de los santos, Madrid, Imprenta Real, 1675. 3 tomos.

RÉAU, Louis, Iconographie de l'Art chrétien. Tome III, Iconographie des saints, Paris, Presses Universitaires de France, 1958-1959. 3 tomes concernant les saints.

ROBBINS, Jeremy, Love Poetry of the Literary Academies in the Reigns of Philip IV and Charles II, London, Tamesis Books Limited, 1997 (Serie A. Monografías, 166).

SÁNCHEZ, Vicente, Lyra poética, Zaragoza, Manuel Román, 1688.

WARDROPPER, Bruce W., «La poesía religiosa del Siglo de Oro», Edad de Oro, 4 (1985), p. 195-210. 